\section{Espacio público versus \\ infraestructura de turismo}

Un análisis a partir de diagramas proyectuales en la ciudad de Mar del Plata, Argentina

Public space versus turist infraestructure: An analysis based on project diagrams in the city of mar del plata, argentina

Espaço público versus infraestrutura de turismo: Uma análise a partir de diagramas projetuais na cidade de Mar del Plata. Argentina

DOI: https://doi.org/10.18861/ania.2021.11.1.3000

Arq. María José Díaz Varela

Becaria interna doctoral CONICET. Facultad de Arquitectura, Urbanismo y Diseño. Universidad Nacional de Mar del Plata.

Argentina

mjdiazvarela@gmail.com

ORCID: https://orcid.org/0000-0002-2340-3481

Arq. Kristina Atanasoska

Becaria Tipo A Universidad Nacional de Mar del Plata. Facultad de Arquitectura, Urbanismo y Diseño. Universidad Nacional de Mar del Plata

Argentina

kristina.atanasoska@gmail.com

ORCID: https://orcid.org/0000-0002-6508-2575

Recibido: 30/09/2020

Aceptado: $24 / 11 / 2020$

Cómo citar:Díaz Varela, M., \& Atanasoska, K. (2020). Espacio

público versus infraestructura de turismo. Anales de Investigación

público versus infraestructura de turismo. Anales de Investigación
Es posible considerar como una problemática latente e conflicto de la utilización de las costas urbanas durante todo el año, en específico las dedicadas a la explotación turística, ya que la infraestructura de turismo está destinada a la temporada alta, e interrumpe con el uso de espacio público y el paisaje.

Dentro de este marco, el objetivo de este trabajo es analizar el proyecto de intervención de la playa Varese en Mar del Plata, realizado por los arquitectos Zak. E y Solla. J. en 2006-2013. La elección de este caso de estudio, se basa en la postura que toma frente a la puja entre el espacio público y la infraestructura de turismo, ya que contempla al habitante como eje rector de la propuesta y el primero en la ciudad en considerar estos aspectos, que resultan de gran interés

La metodología propuesta para el análisis, es el de diagramas proyectuales, los cuales permiten visualizar las características y relaciones principales de la intervención. Debido a esta es posible generar recomendaciones y estrategias proyectuales, desde una perspectiva disciplinar, las cuales es relevante considerar en el programa arquitectónico de futuras intervenciones, en las costas urbanas

Palabras clave: Paisaje, infraestructura urbana, programa arquitectónico, costa urbana, espacio público, infraestructura de turismo.
It is possible to consider as a latent problem the conflict of the use of the urban coast throughout the year, especially the area dedicated to the tourist exploitation, since the tourist infrastructure is destined for the high season, and interrupts with the public space and the landscape. The objective of this work is to analyze the intervention project of the Varese beach in Mar del Plata, carried out by the architects Zak E. and Solla J. in 2006-2013. The choice of this case study is based on the position it takes regarding the bid between the public space and the tourism infrastructure, since it considers the inhabitant as the guiding axis of the proposal and is the first in the city to consider these aspects, which are of great interest. The methodology proposed for the analysis is that of project diagrams, which allow visualiziation of the main characteristics and relationships of the intervention. Due to this, it is possible to generate recommendations and project strategies from a disciplinary perspective, which are relevant to consider in the architectural program of future interventions on urban coasts.

Keywords: Landscape, urban infraestructure, architectonical program, urban coast, public space, tourist infraestructure.
É possível considerar como uma problemática latente o conflito da utilização das costas urbanas durante o ano especificamente as dedicadas à exploração do turismo, já que a infraestrutura turística está destinada à alta temporada e interrompe o espaço público e a paisagem. O objetivo deste trabalho é analisar o projeto de intervenção da praia Varese em Mar del Plata, realizado pelos arquitetos Zak. E. e Solla J. em 2006, a partir de diagramas projetuais que permitem visualizar as caracteristic recomendač̃es de uma perspectiva disciplingr para programa dos projetos arquitetônicos nas costas urbanas.
Palavras-chave: Paisagem, infraestrutura urbana programa arquitetônico, costa urbana, espaço público, infraestrutura de turismo 


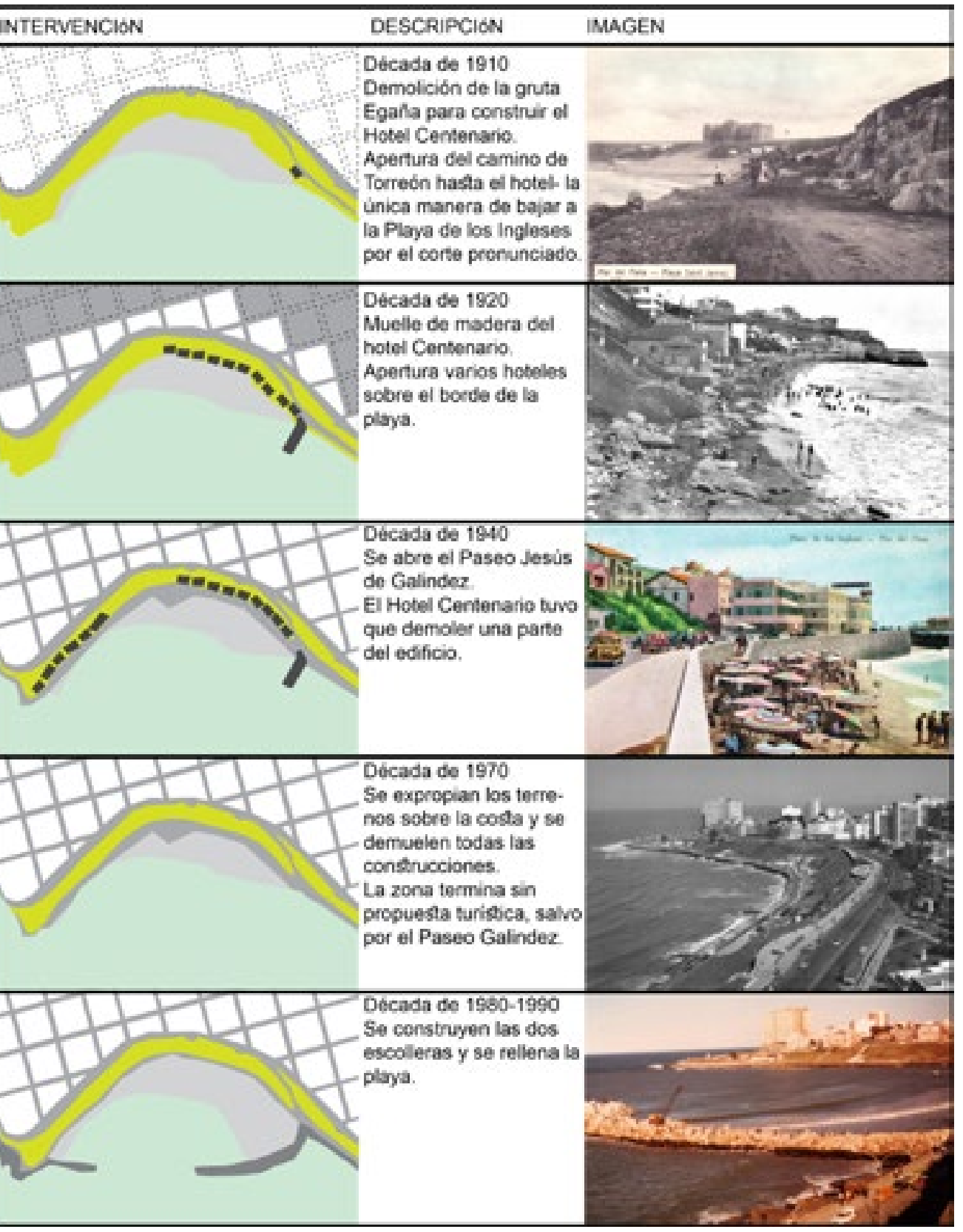

La arquitectura amplía su capacidad de comunicación fundamentalmente a través de la forma, relacionándose con la historia y la memoria colectiva. Pensar una ciudad de todo el año supone quebrar la histórica relación entre la costa y el verano, en una ciudad que dejó de ser la idílica villa balnearia a convertirse además en una ciudad intensamente poblada que disfruta cotidianamente de su borde costero. (Solla y Zak 2012)

Las intervenciones en las costas urbanas, abordadas desde diferentes perspectivas, permiten reconocer conflictos y pujas de intereses a través del tiempo. Estas problemáticas son posibles de interpretar como un sistema que influye en las dinámicas de la ciudad y las costas, siendo la infraestructura del turismo una de las variables que pesan dentro de las mismas. Frente a este debate, la hipótesis de que potencian el uso del espacio público en las costas que potencian el uso del espacio público en las costas y del proyecto, y aportan a la construcción de un saber disciplinar.

El objetivo de este trabajo es analizar las relaciones entre el paisaje, el espacio público y la infraestructura de turismo que influyen en el programa del proyecto arquitectónico para poder generar recomendaciones y estrategias proyectuales, las cuales puedan forjar aportes cualitativos a proyectos con problemáticas similares. Para ello, nos centramos en el análisis de la intervención en Varese de los arquitectos Solla José y Zak Eduardo (2006-2013) en la ciudad Mar del Plata, ya que es el proyecto más reciente de coyuntura que impacta en la estructura urbana de la ciudad.

La problemática en la que se desarrolla esta intervenció esta relacionada con las bases que se desarrollan dentro del urbanismo y los planes urbanos, los cuales surgen como respuesta a los conflictos de la ciudad. Esta disciplin provee herramientas de interpretación y propuestas, que en el caso de las ciudades con costas o riberas permiten in problemáticas entre el espacio público y la y son testigo de un espacio de discusión sobre cómo se constituye la ciudad moderna. A su vez se consideran a las costas como un lugar que abarca aspectos sociales políticos y culturales, que complejizan la problemática y dan cuenta de la "heterogeneidad de las prácticas y procesos que inciden en la construcción de la ciudad" (Fedele 2011, 22). El estudio de estos planes sirve para la producción de instrumentos de actuación material y políticas y permiten a su vez sintetizar el conocimiento de los proyectos de la ciudad, absorber y procesar ideas de debate urbano y traducir los cambios de los paradigmas urbanísticos, exponiendo resoluciones a los conflictos espaciales.

En específico para este análisis es necesario definir a la infraestructura de turismo, la cual se entiende como aquella comprendida por las instalaciones, edilicias y administrativas, que permiten el desarrollo del turismo. Otros de los conceptos a definir son los de paisaje y espacio público, ya que son parte fundamental de la problemática. El paisaje es posible considerarlo como las expresiones de territorio singulares y de la cultura colectiva emocional, que logran configurar elementos esenciales de las ciudades (Folch y Bru 2017). Como espacio público se entienden a los lugares que permiten expresar "la democracia en su dimension territorial. Es el espacio de uso colectivo." (Borja 2011, 39) . Estos conforman lugares que forman parte de paisaje urbano, comprendiendo que la "ciudad, espacio público y arquitectura resultan consustanciales para poder aluir a ese texto envolvente del habitar que llamamos paisaje urbano." (Kuri 2012, 07).

Los conflictos en las costas de las ciudades de Buenos Aires, Rosario y Santa Fe (Principales centros urbanos con costa en Argentina), se caracterizan por la puja entre el espacio público y la industria e infraestructura portuaria.

Figura 1. Evolución de las intervenciones en la playa Varese entre 1910 y 1990 
A diferencia de estas, la ciudad de Mar del Plata está definida por su carácter turístico, permitiendo considerar su costa como "un campo simbólico y receptor de las posible conexiones entre estratos sociales diferentes en el que interactúan contemporáneamente las élites dominantes junto a formas sociales populares" (Pastoriza y Zuppa 2004 106). Por este motivo, la playa y los balnearios son testigos de los procesos de transformación social que sufrió la ciudad, caracterizada por las élites argentinas desde fines del Siglo XIX hasta los anos 40, seguida de las clases medias hasta los 60 y que culmina siendo representante de las
clases trabajadoras, con la intervención de los sindicatos clases trabajadoras, con la intervención de los sindicatos siglo XX. La evolución de las características de la ciudad está ligada
a las alteraciones de la configuración social, posibilitando observar la puja entre el paisaje y, en este caso, Ia infraestructura turística. En esta puja, se desarrollan desde diferentes intervenciones: hoteles, complejos gastronómicos e infraestructura de transporte; que se contraponen con el paisaje y el espacio público.

Físicamente la costa marplatense se caracteriza por ser la culminación del sistema de Tandilia, que al encontrarse con el Océano Atlántico conforma bahías donde se instalan los primeros balnearios como La Perla, Bristol y la Playa de los Ingleses (actualmente Varese). Las primeras ocupaciones de este último balneario fueron equipamientos gastronómicos y hoteleros, siendo el Centenario (Figura 1) uno de los más reconocidos ya que modifico sus caracteristicas a través del tiempo, llevando el sector el nombre de su dueño (Diario La Capital 2016).

Puede considerarse al sector de Varese como consecuencia de estas pujas de territorio, ya que deja registro de los diferentes proyectos de ciudad en relación con la costa. En este sentido las intervenciones en Varese realizados por inversores privados en los años cuarenta del siglo XX se apropian del espacio público sin tener en cuenta al habitante y el paisaje, la intervención realizada por los arquitectos Solla y Zak representan una ruptura a esta concepción de explotación de los recursos. Además se cree significativo que tiene en cuenta el sistema de intervenciones costeras previas.

Para poder desarrollar la problemática se desglosan tres pros desarrollan los conceptos denominado "Metodología", se como herramientas de investigación; en el segundo, la "Intervención", se realiza una caracterización del proyecto de Varese, observando las decisiones formales llevadas a vabo por los autores: y en el último "El diagrama como herramienta", se analizan las interacciones entre los distintos aspectos de la intervención, las cuales permiten obtener recomendaciones y estrategias proyectuales de interés.

Metodología

Es posible considerar al proceso proyectual como una metodología de análisis. Para comprenderlo se entiende que en el campo de la disciplina arquitectónica es fundamental pensar, reflexionar, proyectar y especular, $y$ que en este sentido deben responder a una gran complejidad de requerimientos desde la sociedad (Forster, 2015). El proyecto puede definirse como un proceso de toma de deciciones, ordenado a partir de un concepto o idea rectora, que se va tranformando y que es posible concebirlo como una estructura evolutiva que se actualiza y nutre constantemente. Los objetivos del mismo pueden resumirse en sintetizar, organizar y reflexionar acerca de los diferentes factores que influyen en las problematicas y el programa arquitectonico.

Para interiorizarse sobre los diagramas, es posible situarlos entre las ideas/conceptos, y el proyecto. Surgen como estrategias para interpretar la "realidad", pues modelan y sintetizan la complejidad del contexto donde se dan las problemáticas. Estos se definen como "vectores geométricos, intentos de visualización de flujos, materias y fenómenos que no tienen forma o figura precisas" (Montaner 2010). Además, operan a partir de parámetros que conjugan acciones para el acercamiento a los problemas, traduciendo a un nuevo lenguaje homogéneo, información heterogénea. Los esquemas abstractos representan relaciones de fuerza que se dan dentro de los factores que intervienen en el problema (Forster et. al. 2008)

Los diagramassirven como herramienta para la compresión de la puja entre el paisaje y el espacio público con la infraestructura de servicio, se plantea la producción de cuatro diagramas servicio, se plantea la produccion de los factores de la problemática en la intervención de Varese esta medotologia permite fortalecer aquellas estrategias que configuran el programa del proyecto arquitectonico. 
La intervención de Playa Varese y Cabo Corrientes realizada por los arquitectos Solla José y Zak Eduardo, surgió a partir del llamado a licitación pública sobre proyecto explotación bajo el sistema de concesión, con el requisito fundamental de poner en valor el lugar, los balnearios los servicios de carácter privado. El predio donde se ubica los se intervención se delimita por las intersecciones de la Av. Colon y la calle A. del Valle con el Bv. Peralta Ramos. EI proyecto se inicia en el año 2006 y finaliza en 2013.

Como premisa para la ejecución de la intervención, los autores plantean "entender el paisaje costero como un derrame natural de la ciudad donde el espacio público es el actor protagónico, un espacio que también debe abandonar sus hábitos acartonados para permitir un uso más contemporáneo del paisaje y del espacio público" (Solla y Zak 2012, 10). Teniendo en cuenta estos conceptos, y su relación con la ciudad y la costa, es que surge esta intervención urbana.

La propuesta consiste en un proyecto lineal que se adapta a la bahía de Varese (Figura 2), con una configuración formal que utiliza materiales como la piedra, la vegetación la arena, el mar y el hormigón, que se muestran en la propuesta como una composición, con la utilización de diferentes recursos formales. A partir de desglosar los componentes que intervienen en el proyecto, se reconocen las principales características, relacionadas con tres subsistemas: el sector de la barranca, las plazas mirador, por ultimo los balnearios y equipamientos gastronomicos.

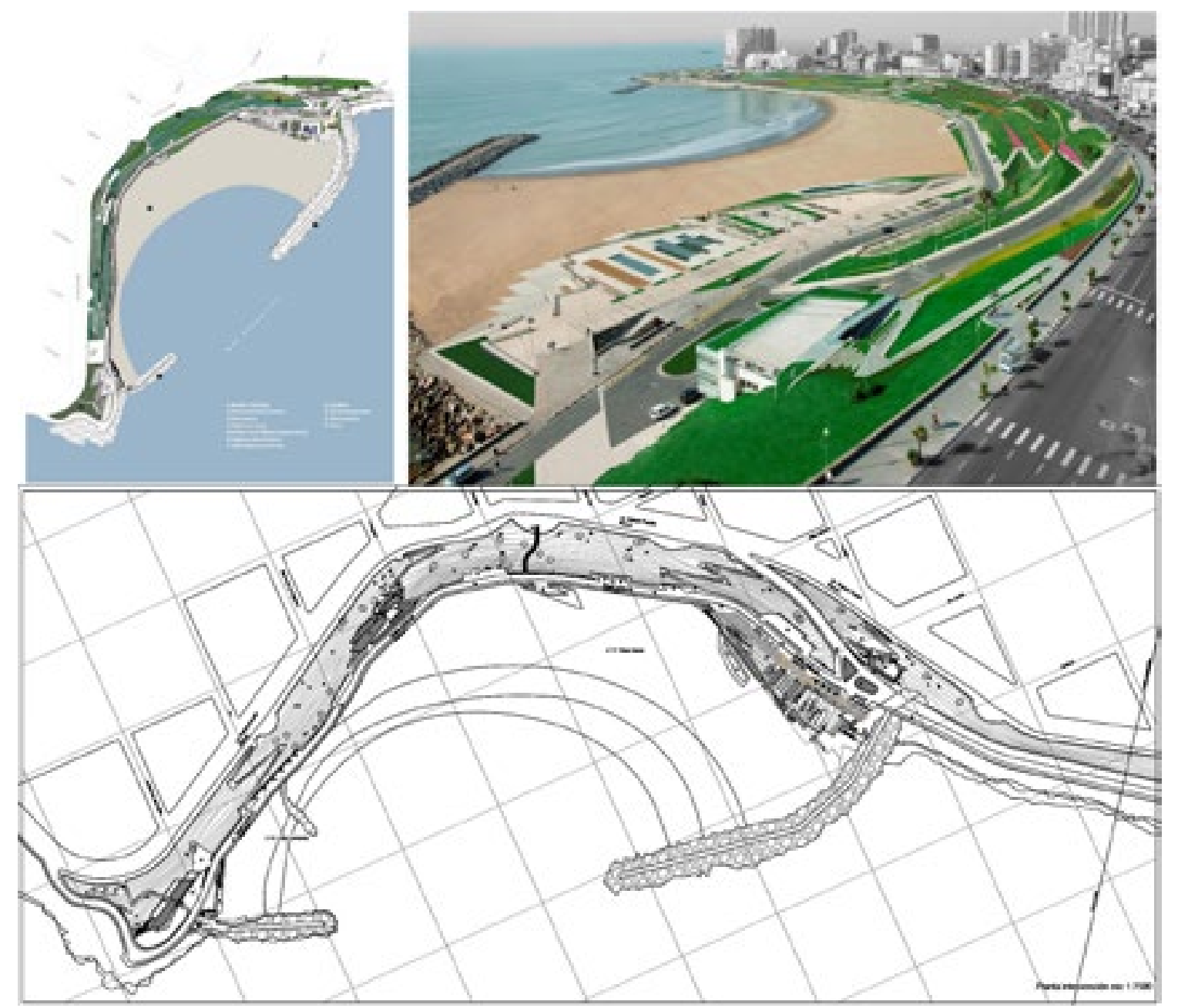

Figura z: Implantación y documentación del proyecto de intervención

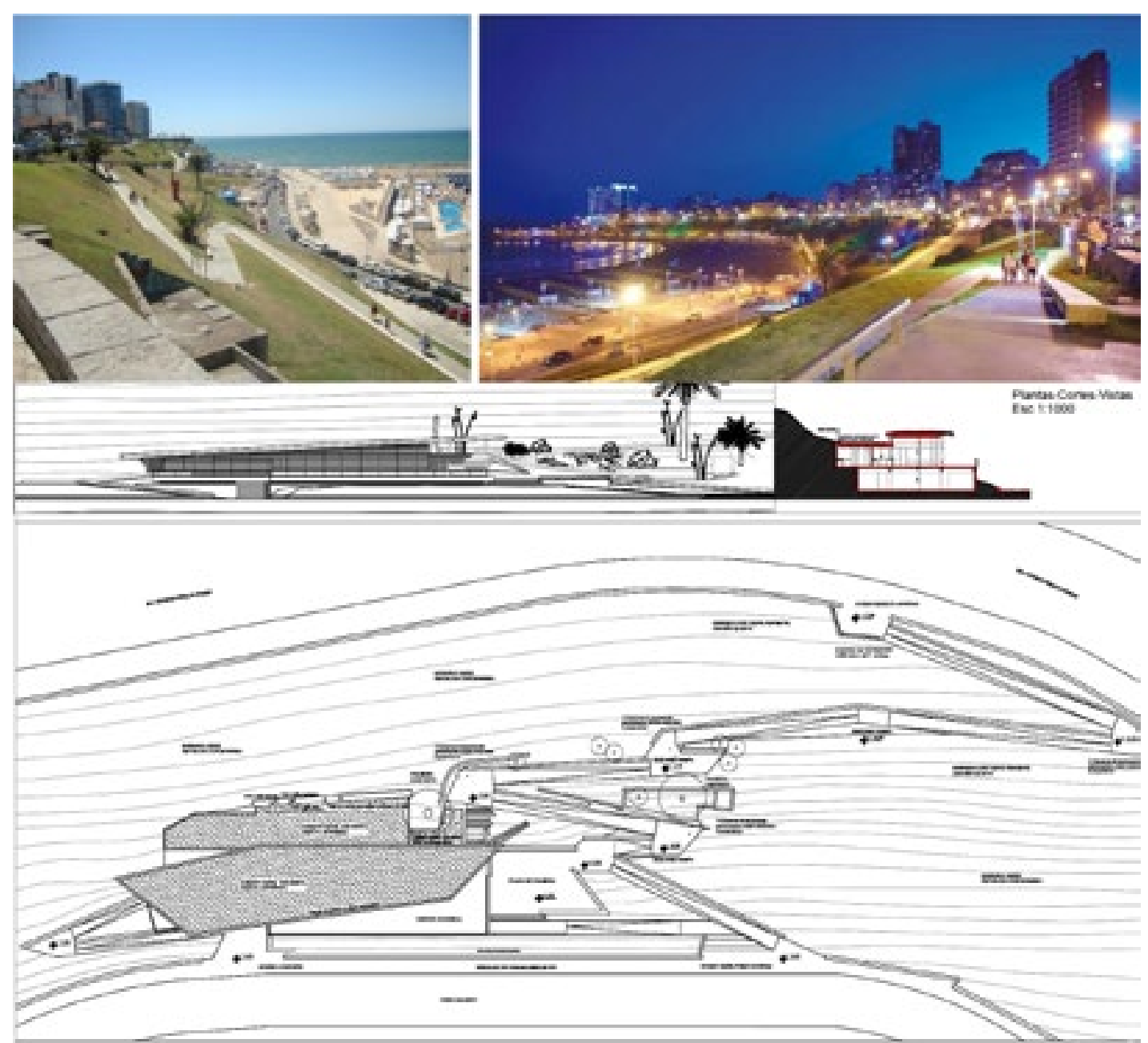

Figura 3: Imágenes y documentación del sector de la barranca, Playa Varese

El sector de la barranca (Figura 3) está caracterizado por los recorridos. Las rampas surgen como conectores entre calle superior y la inferior permitiendo la accesibilidad, pero a su vez suman "innumerables experiencias y relaciones con el paisaje" (Solla y Zak 2012), que se potencian al variar 
las direcciones y alturas de observación. Dentro de este sector también se destaca el tratamiento de la vegetación que acompaña la composición de las circulaciones, sumándose las luminarias como parte de la propuesta. Estas consideraciones del proyecto permiten que se use en diferentes momentos del año y diferentes horarios del día. El segundo subsistema, al cual se denomina plazas mirador (figura 4), se destaca por ser un espacio público y funciona como una antesala al mar, permitiendo acceder a la playa a través de rampas y escaleras Otro de los aspectos a destacar son los espacios de estar que varían el equipamiento y cualidades dependiendo si su ubicación es sobre el borde, en maceteros o conformando espacios de reunión Las luminarias también potencian estos espacios diferenciando la circulación de los lugares de estar. Estos miradores es posible considerarlos plazas contemporáneas que permiten diversidad de actividades respondiendo a los nuevos modos de habitar.

El proyecto de los balnearios y los equipamientos gastronómicos (Figura 5) surge de la premisa de articular con el paisaje nuevos servicios para los habitantes, y es por este motivo que sobre la barranca los diferentes locales se insertan en la pendiente, sin invadir las visuales de los recorridos peatonales. A su vez, en el intento de mimetizar la arquitectura con el paisaje y el entorno, las cubiertas son tratadas como un espacio público, generándose nuevos lugares sobre esta quinta cara del edificio para poder contemplar el paisaje. Las piedras que son parte de la barranca pasan a ser un componente del interio de los equipamientos gastronómicos. Los balnearios se encuentran en la playa, pero no se distinguen a simple vista, ya que están por debajo de la plaza mirador, enfatizando aún más la fusión con el paisaje. Los mismos cuentan con cocheras y servicios necesarios, pero desde la decisión proyectual no se reconocen del paseo costero.
Esta descripción de los subsistemas de la intervención permite profundizar sobre las características generales compresión de cómo el concepto principal que plantearon los autores la importancia del espacio público por sobre privado, se manifiesta con coherencia en cada una de las diferentes actuaciones.

\section{El diagrama como herramienta}

En el segundo apartado se realizó una descripción que permite entender las características y los componentes principales de la intervención en Varese, pero no se profundiza en la manera en que los mismos se relacionan profundiza en la manera en que los mismos se relacionan (2008) y Montaner (2010), se analiza el proyecto a parti de diagramas y esquemas analíticos que tienen como objetivo divisar la puja entre el espacio público, el paisaje y la infraestructura de turismo.

En el primer diagrama (Figura 6) se sintetizan la relación entre las características de la costa de Mar del Plata y la ciudad, observando como principales componentes la estructura urbana, las playas, las plazas y parques, el puerto y el sector de intervención dentro de este sistema. Al ser un diagrama que simplifica los diferentes componentes de la costa de la ciudad, se toma como decisión que la representación no tenga una escala precisa, ni una forma exacta, en esta síntesis se ve los fragmentos de las diferentes intervenciones de como la estructura urbana llega a la costa.

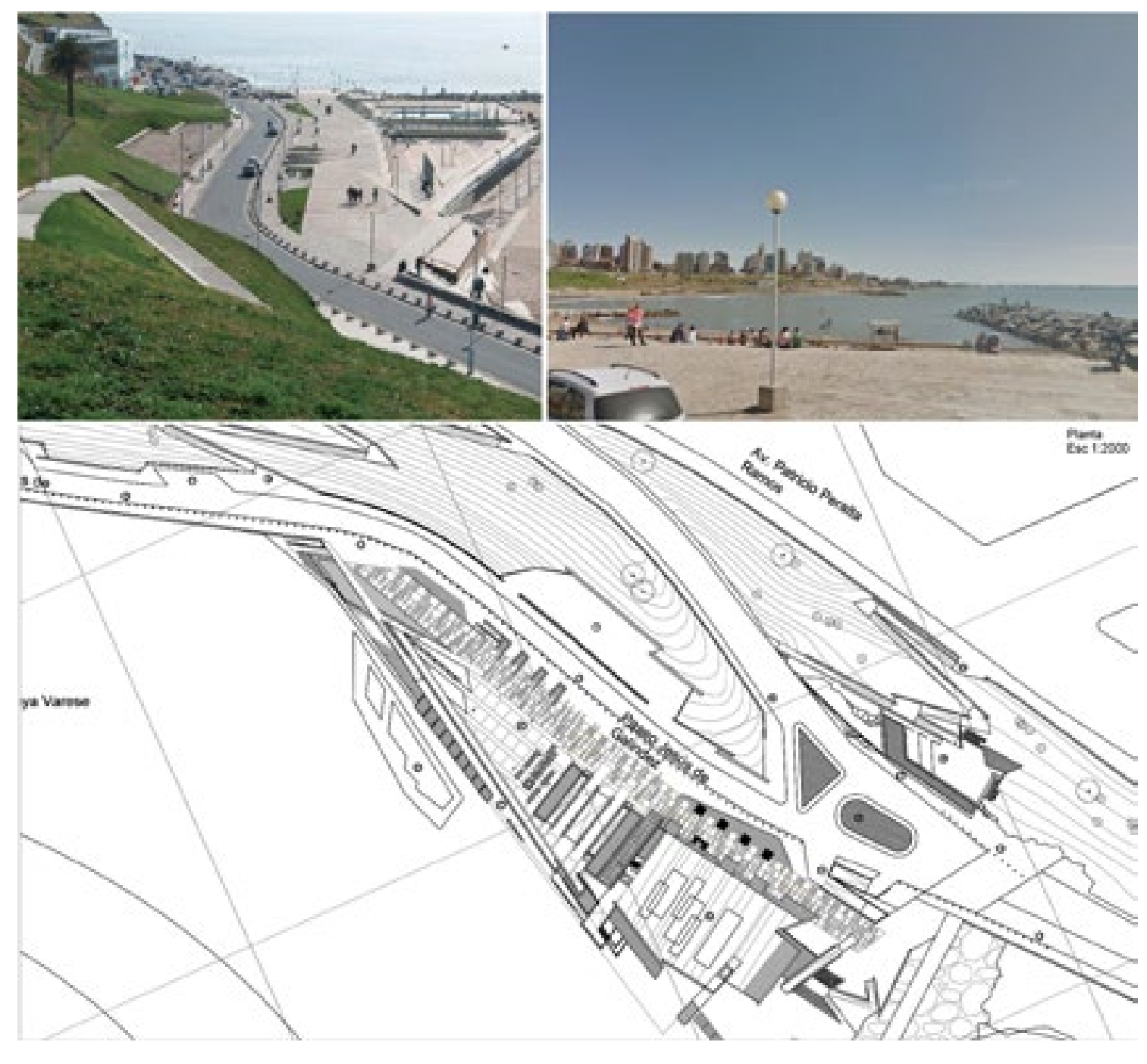

Figura 4: Imágenes y documentación de las plazas mirador, Playa Varese. 

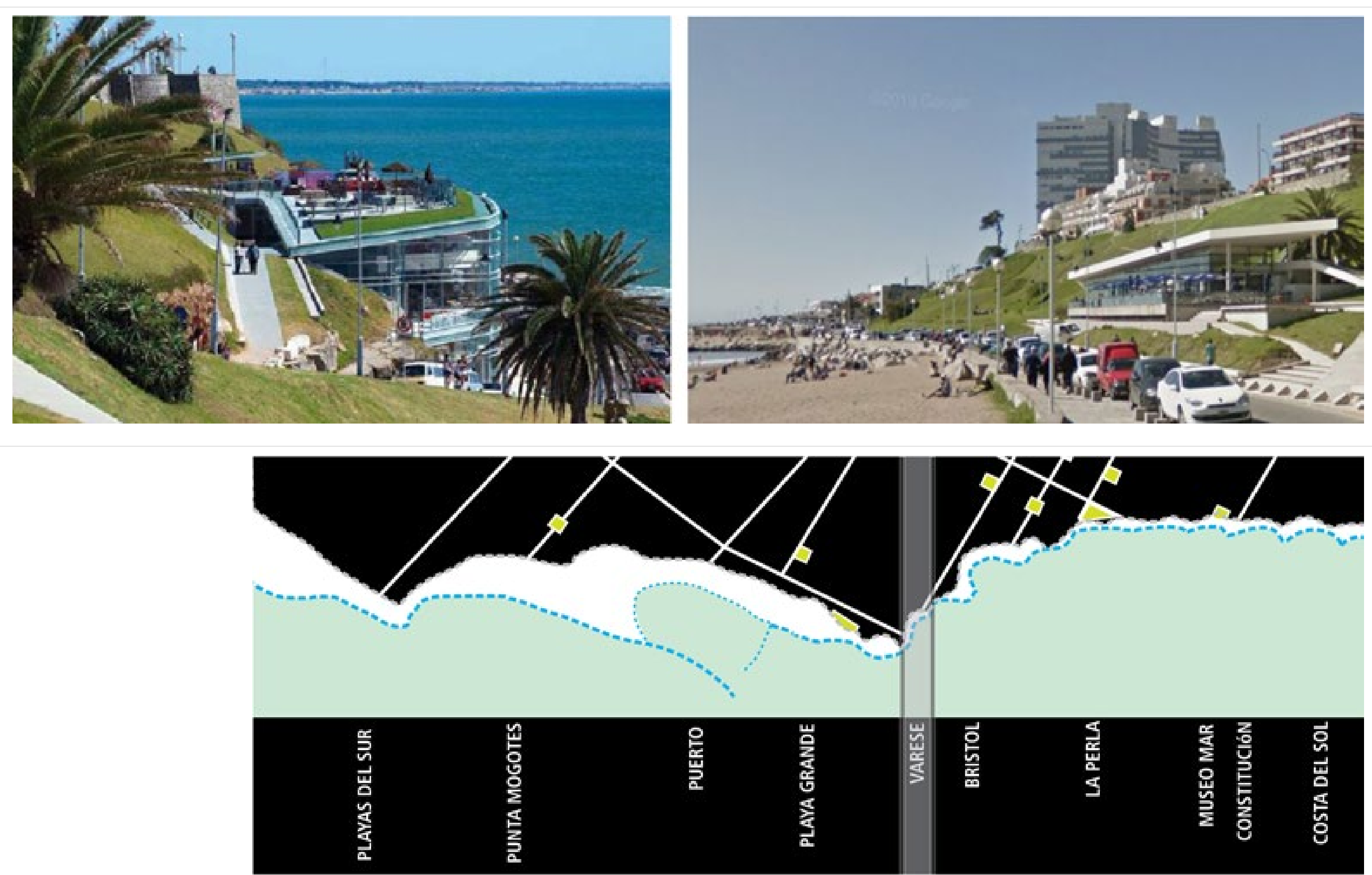

Figura 6: Estructura urbana e intervenciones costeras 




El barranco de la Playa Varese

Figura 7: La intervención como costura. Varese, Mar del Pla
En una escala de aproximación a la intervención, surge (Figura 7), donde se representa la problemática de accesibilidad y conexín con la ciudad previa y posterior a la intervención. En este esquema los componentes que se ponen en juego son la ciudad, la barranca elBv. Peralta Ramos, el Jaseo Galindez la arena el mar.A diferencia del Rnterior, el diagrama escom arenay y permite observar que a partir de la intervención se realizan costuras urbanas entre los diferentes niveles que posibilita una mayor accesibilidad de los habitantes que polaya, refuerza el espacio público con las bajades peatonales y disfrute del paisaje a partir de los diferentes recorridos propuestos por la intervención.

En el tercer diagrama (Figura 8) se representan los recorridos peatonales, los puntos de contemplación del paisaje y los recorridos vehiculares A partir de su realización el objetivo de este es contrastar los recorridos para poder visualizar qué aspectos tienen mayor jerarquía dentro del proyecto, en este caso los recorridos peatonales son prioritarios sobre las circulaciones vehiculares. Este aspecto es significativo ya que potencia una movilidad comprometida con el paisaje.

El último diagrama (Figura 9) sintetiza las diferentes superficies de espacio público (con y sin vegetación), infraestructura turística (equipamiento gastronómico y balnearios) y la infraestructura vehicular (circulaciones y cocheras), que permiten contrastar el valor cuantitativo que se le da a cada uno de los aspectos mencionados dentro de la propuesta, específicamente el espacio público prevalece por sobre el privado, deja en claro así la postura de la intervención, un proyecto de inversión privada puede beneficiar a los usuarios de la costa si se considera desde el programa del proyecto arquitectónico.
Los diagramas realizados permiten el análisis de las relaciones entre los diferentes factores que intervienen en el proyecto, logrando visualizar en cada caso las premisas de los autores. Se destaca que los diagramas sirven tanto para el análisis como para el proceso del proyecto. La implementación de este tipo de metodologías cualitativas sintetiza elementos que son elegidos de forma subjetiva, que afectan al proyecto arquitectónico. 


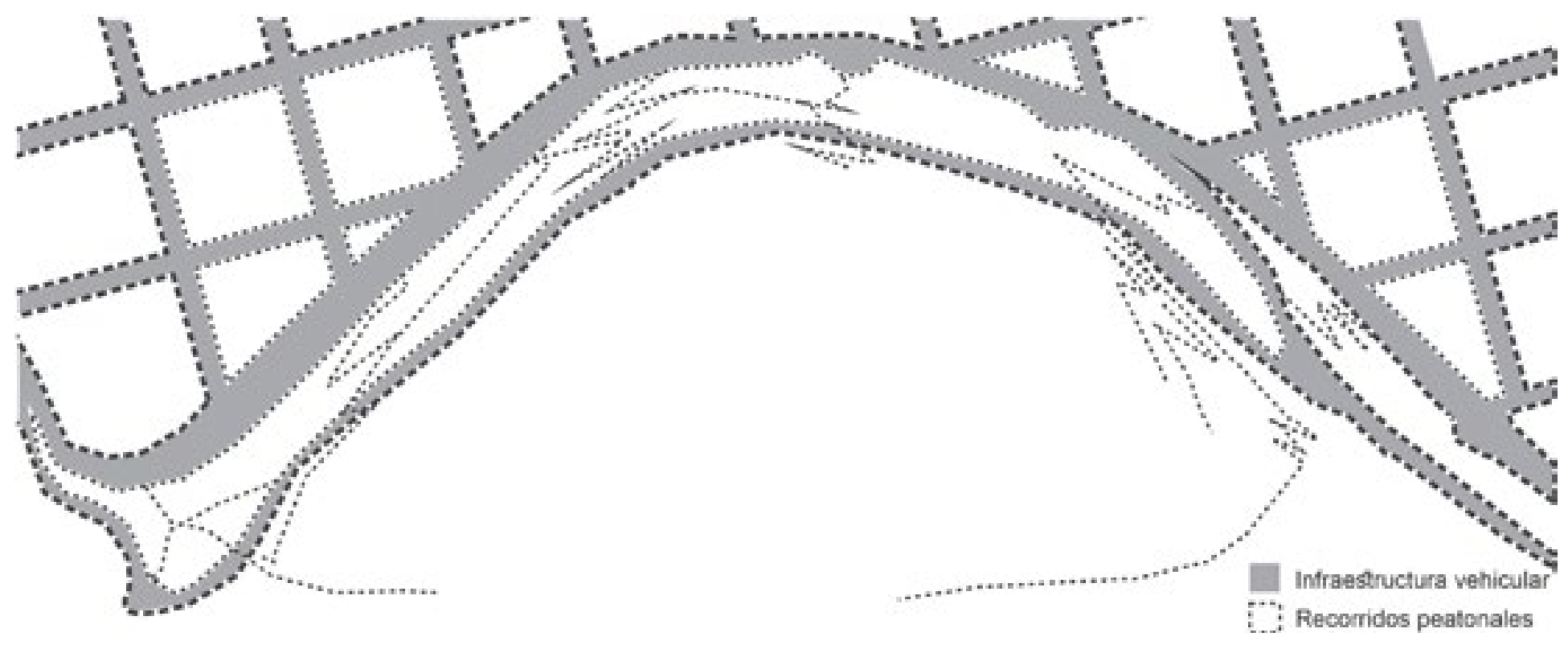

Figura 8: Recorridos peatonales e infraestructura vehicular. Varese, Mar del Plata.

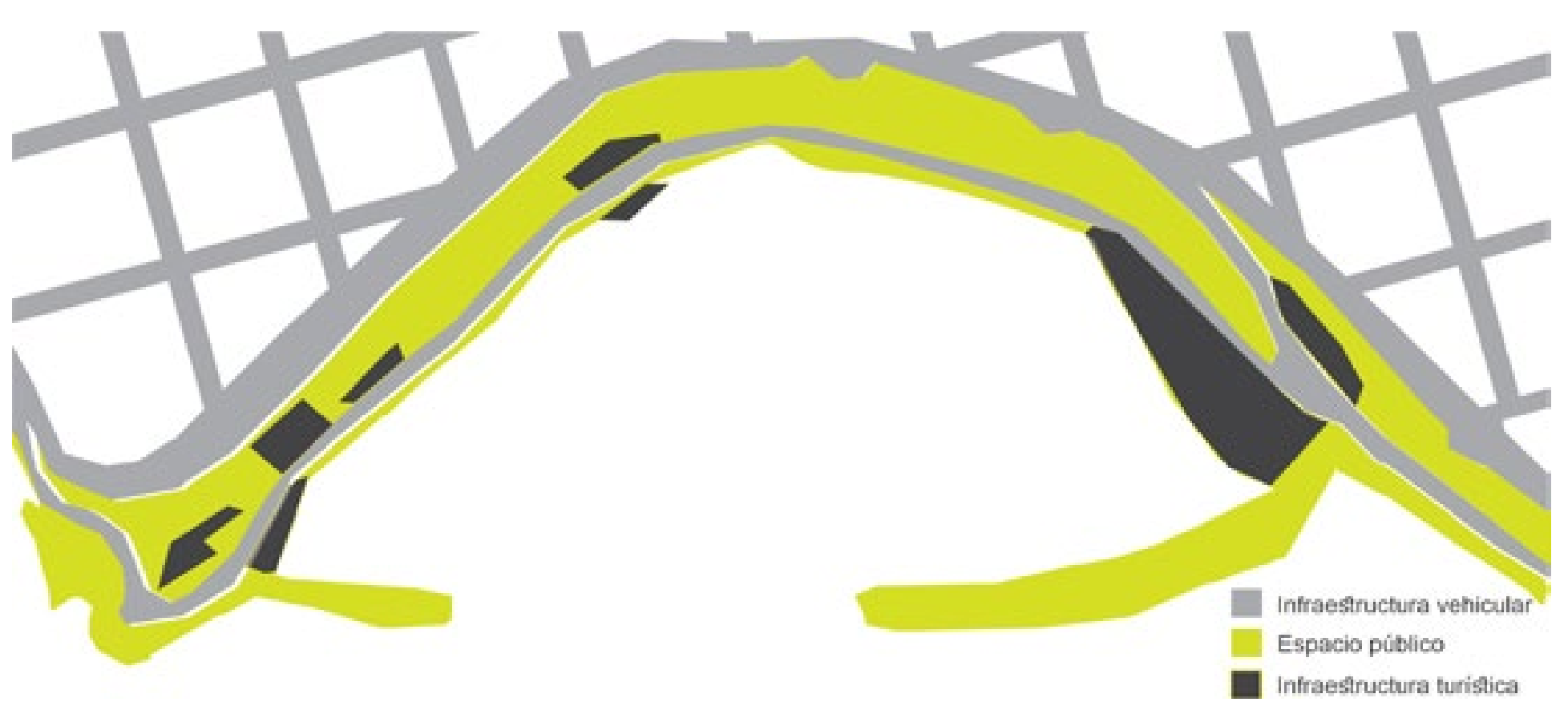

Figura 9: Espacio público versus infraestructura de turismo y vehicular. Varese, Mar del Plata
Conclusiones

“Por eso la ausencia en este proyecto es más importante que la presencia. La ausencia de una importante que la presencia. La ausencia de una rimbombantes, en favor de una arquitectura silenciosa donde el paisaje siga siendo lo que es." silenciosa donde
(Solla y Zak 2012)

Este trabajo permite aproximarse a comprender las relaciones entre el proyecto y los lugares costeros de la ciudad, a partir de visualizar cómo desde una práctica privada puede generarse espacio público, que colabora y potencia un vacío urbano costero, logrando ser utilizado potencia un vacío urbano costero, logrando ser utilizado
todo el año. La intervención surge en un sistema urbano que propone diversas soluciones a la misma problemática, que propone diversas soluciones a la misma problemática, y en este sentido su respuesta a ese contexto puede espacio público. Es posible rescatar que la propuesta formal realizada potencia la fusión entre las formas arquitectónicas y las formas naturales, "disimulando la intervención del hombre para conseguir una percepción feliz de una naturaleza sin profanar". (Puga y Sáez 2012) logrando una composición que genera nuevos paradigmas para las intervenciones del espacio público en relación a la costa.

Los diagramas como recurso para el análisis permiten visualizar las relaciones y pujas entre los factores que determinan el proyecto, $y$ a través de abstracciones facilitan la comprensión de las ideas principales. A partir de estos fue posible observar el contexto de la costa de Mar del Plata y como la propuesta se inserta dentro de este sistema, otro de los puntos de análisis fue observar como la intervención conecta la ciudad con la playa y los balnearios, y funciona como una costura entre los diferentes niveles de la costa. A nivel de proyecto fue posible contrastar los recorridos peatonales los cuales sobresalen sobre los vehiculares, con respecto a la relación cuantitativa se observa que el espacio público predomina sobre la infraestructura de turismo. Esta propuesta que se desarrolla en el seno de la puja entre turismo y espacio público, logra posicionarse en un punto donde a partir de la financiación privada (Infraestructura Turística) es posible constituir proyectos con fines sociales que se utilizan todo el año. Y a su vez
desde el hacer proyectual aportan con convicción a la calidad del espacio público apentro de la ciudad. A partir de este análisis consideramos que las recomendaciones para el programa del proyecto arquitectónico de intervenciones de las costas urbanas se pueden sintetizar en cuatro estrategias:

Conectar la estructura urbana existente al proyecto, considerando la accesibilidad de los habitantes como prioridad.

Fortalecer los recorridos peatonales, entendiendo como significativas las vistas del paisaje y su

relación con el espacio público.

La infraestructura de turismo debe ser flexible para su uso todo el año. Las mismas deben garantizar no obstruir el disfrute del paisaje

existente.

Cualificar los espacios públicos para que permitan su uso en diferentes horarios del día y épocas del año.

Para finalizar, cabe destacar que este tipo de análisis puede llevarse a cabo en más de una intervención o propuesta sobre la costa, no sólo en la ciudad de Mar del Plata, sino también en regiones de características similares pudiendo considerar estas recomendaciones para los programas de los proyectos. Estas cuatro estrategias proyectuales complementan el programa de una posible intervención en las costas y refuerza la hipotesis de este trabajo, ya que estas pujas se dan en muchas ciudades donde el principal ingreso es a partir del turismo, y es por ello que estos análisis generan una base a tener en cuenta a la hora de constituir planes estratégicos, con el objetivo potenciar las características del espacio público y el paisaje de las costas. 
Aprobación final del artículo: editora en jefe Arq. Carla Nóbile.

Contribución de autoríala elaboración del artículo es obra única de los autores.

Referencias

BORJA, J. (2011) Espacio público y derecho a la ciudad. Viento Sur (11) 39.

DIARIO LA CAPITAL. La actual playa Varese hace más de un siglo. La Capital. Mar del Plata, 19 de Julio de 2016.

FEDELE, J. (2011) El río en la ciudad del plan. Urbanismo sobre las riberas de la pampa argentina Santa Fe: Ediciones UNL

FOLCH, R. \&BRU,J. (2017) Ambiente, territorioy paisaje. Valoresyvaloraciones. Barcelona: Editorial Barcino.

FORSTER, S. (2015) Procesos de distinción. Matéricos Periféricos(12) 185-187.

FORSTER, S.; BOCANI, R. \& CÁRDENAS, G. (2008) Metodologia y desarrollo. Recuperado desde: https://cargocollective.com/integracionesheterogeneas/Metodologia-y-desarrollo.

KURI, R. (2012) El paisaje urbano. Revista INEX (1) 7.

MONTANER, J. (2010) Arqueología de los diagramas. Cuadernos de Proyectos Arquitectonicos (1). PASTORIZA , E. \& ZUPPA, G. (2004) La conquista de las riberas. Política, cultura, turismo y democratización. Mar del Plata (1886-1970). TRACE (45) 93-109.

PUGA, M. \& SÁEZ, J. (2012) Observaciones al margen. Revista INEX (1) 31-34.

SOLLA, J. \& ZAK. E. (2012) Intervención Playa Varese/Cabo Corrientes. Mar del Plata. Revista INEX
Figura 1. Evolución de las intervenciones en la playa Varese entre 1910 y 1990. Fuente: Elaboración propia en base a http://fotosviejasdemardelplata.blogspot.com/2013/10/ hotel-centenario-de-luis-varese htm.

Figura 2. Implantación y documentación del proyecto de intervención Varese Fuente: Solla, J., y Zak, E. (2012) y documentación brindada por los proyectistas.

Figura 3. Imágenes y documentación del sector de la barranca, Playa Varese. Fuente: Solla, J., y Zak, E. (2012) y documentación brindada por los proyectistas.

Figura 4. Imágenes y documentación de las plazas mirador, Playa Varese. Fuente: Solla, J., y Zak, E. (2012). y documentación brindada por los proyectistas.

Figura 5. Imágenes de balnearios y equipamientos, Playa Varese. Fuente: Solla, J., y Zak, E. (2012)

Figura 6. Estructura urbana e intervenciones costeras. Mar del Plata. Fuente: Elaboración propia.

Figura 7. La intervención como costura. Varese, Mar del Plata. Fuente: Elaboración propia.

Figura 8. Recorridos peatonales e infraestructura vehicular. Varese, Mar del Plata. Fuente: Elaboración propia.

Figura 9. Espacio público versus infraestructura de turismo y vehicular. Varese, Mar del Plata. Fuente: Elaboración propia. 